\title{
Physiological response of wild rainbow trout to angling: impact of angling duration, fish size, body condition, and temperature
}

\author{
Julie M. Meka ${ }^{\mathrm{a}, *}$, Stephen D. McCormick ${ }^{\mathrm{b}}$ \\ a United States Geological Survey, Alaska Science Center, Biological Science Office 1011 E. Tudor Road MS701, Anchorage, AK 99503, USA \\ ${ }^{\mathrm{b}}$ United States Geological Survey, Conte Anadromous Fish Research Center One Migratory Way, P.O. Box 796, Turners Falls, MA 01376, USA
}

Received 4 June 2004; received in revised form 13 October 2004; accepted 19 October 2004

\begin{abstract}
This study evaluated the immediate physiological response of wild rainbow trout to catch-and-release angling in the Alagnak River, southwest Alaska. Information was recorded on individual rainbow trout $(n=415)$ captured by angling including landing time and the time required to remove hooks (angling duration), the time to anesthetize fish in clove oil and withdraw blood, fish length and weight, and water temperature at capture locations. Plasma cortisol, glucose, ions (sodium, potassium, chloride), and lactate were analyzed to determine the effects of angling duration, fish size, body condition, and temperature. Levels of plasma ions did not change significantly during the observed physiological response and levels of plasma glucose were sometimes influenced by length $(2000,2001)$, body condition (2001), or temperature (2001). Levels of plasma cortisol and lactate in extended capture fish (angling duration greater than $2 \mathrm{~min}$ ) were significantly higher than levels in rapid capture fish (angling duration less than $2 \mathrm{~min}$ ). Rapid capture fish were significantly smaller than extended capture fish, reflecting that fish size influenced landing and handling times. Fish size was related to cortisol and lactate in 2002, which corresponded to the year when larger fish were captured and there were longer landing times. Body condition (i.e., weight/length regression residuals index), was significantly related to lactate in 2000 and 2001. Water temperatures were higher in 2001 (mean temperature \pm S.E., $13 \pm 2{ }^{\circ} \mathrm{C}$ ) than in 2002 $\left(10 \pm 2{ }^{\circ} \mathrm{C}\right)$, and fish captured in 2001 had significantly higher cortisol and lactate concentrations than fish captured in 2002. The pattern of increase in plasma cortisol and lactate was due to the amount of time fish were angled, and the upper limit of the response was due to water temperature. The results of this study indicate the importance of minimizing the duration of angling in order to reduce the sublethal physiological disturbances in wild fish subjected to catch-and-release angling, particularly during warmer water temperatures. It is also important to note that factors such as fish size may influence both the duration of angling and subsequent physiological response.
\end{abstract}

(C) 2004 Elsevier B.V. All rights reserved.

Keywords: Rainbow trout; Oncorhynchus mykiss; Angling; Stress physiology; Temperature; Cortisol; Glucose; Lactate; Weight/length residuals; Body condition

\footnotetext{
* Corresponding author. Tel.: +1 907786 3917; fax: +1 9077863636.

E-mailaddresses: julie_meka@usgs.gov (J.M. Meka), stephen_mccormick@usgs.gov (S.D. McCormick).
} 


\section{Introduction}

Fish captured by catch-and-release angling are often subjected to physical exhaustion during the landing process, lethal and non-lethal hooking injuries, and handling and air exposure during the hook removal process. In addition to studies focusing on the relationship between hooking injury and mortality (e.g., Muoneke and Childress, 1994), many studies indicate the importance of the physiological disturbance during the angling process as contributing to mortality (Wydoski et al., 1976; Dotson, 1982). In general, studies documenting the physiological disturbance of wild fish from hooking stress have found minimal mortality (Wydoski et al., 1976; Gustaveson et al., 1991; Tufts et al., 1991; Pankhurst and Dedual, 1994; Booth et al., 1995; Brobbel et al., 1996). However, mortality may increase when fish are angled at warmer water temperatures (Dotson, 1982; Titus and Vanicek, 1988; Wilkie et al., 1996). There are also sublethal effects that may be induced by physiological changes provoked by a stress event including changes in reproductive behavior or function (Campbell et al., 1992; Kieffer et al., 1995; Cooke et al., 2000), disease resistance (Pickering and Pottinger, 1989), growth suppression or decrease in appetite (Gregory and Wood, 1999), post-release predation (Cooke and Philipp, 2004), and other behavioral effects such as changes in social hierarchies and migratory behavior (Lewynsky and Bjornn, 1987; Mäkinen et al., 2000). Physiological disruptions from stress events can be considered cumulative (Barton et al., 1986); therefore, it is possible that fish caught and released several times during a fishing season may be more vulnerable to these types of sublethal effects.

Increases in levels of plasma cortisol after the onset of an acute stress, as well as secondary physiological responses such as hyperglycemia, hyperlacticemia, and ionic disturbance, have been measured to assess the effects of landing time (Wydoski et al., 1976; Gustaveson et al., 1991; Pankhurst and Dedual, 1994; Thorstad et al., 2003). Recent studies have also addressed the effect of hook type on the ease of removal and handling time by comparing various hook types, such as circle versus standard "J" hooks and barbed versus barbless hooks (e.g., Cooke et al., 2001, 2003), and by measuring the physiological response to air exposure, which commonly occurs during the hook removal process (Ferguson and Tufts, 1992; Cooke et al., 2001).
Studies examining the physiological response or hooking mortality of angled wild fish typically hold fish after capture, which can potentially bias study results by the addition of confinement and crowding stress (Wright, 1972) and further injury from confinement (McLaughlin et al., 1997; Cooke and Hogle, 2000). While it is recognized that the most comprehensive type of study to evaluate the effects of catch-and-release fishing in wild fish includes monitoring the behavior and recovery of angled fish after release (Cooke et al., 2002), the associated injuries and potential addition of confinement stress make holding fish after capture undesirable for some fish populations and species.

An extensive amount of research has been conducted to evaluate the magnitude and duration of the physiological response of rainbow trout to exhaustive exercise in hatchery or laboratory environments (Wood et al., 1983; Woodward and Strange, 1987; Pickering and Pottinger, 1989). However, little in situ research has been completed on the physiological response of wild rainbow trout to angling in their natural environment. The Alagnak Wild River, a conservation unit partially located within the Katmai National Park and Preserve of the National Park Service in southwest Alaska, supports a naturally reproducing population of wild rainbow trout (Oncorhynchus mykiss) which are targeted by a popular catch-and-release only sport fishery. Catchand-release angling regulations were implemented due to concerns over the health of the trout population that is subjected to intense angling pressure, with reports from local guides and anglers of high incidences of hooking scars and decreasing fish size and abundance (Meka et al., 2003). Approximately $30 \%$ of Alagnak River rainbow trout have at least one scar purportedly due to previous hooking, indicating that a substantial portion of the population is subjected to multiple angling captures (Meka, 2004). The objectives of this study were to evaluate the initial stress response in Alagnak River rainbow trout in relation to landing time and handling time during the hook removal process, fish size, body condition (residual scores from regression of body mass on body size), and fluctuating seasonal water temperatures, by measuring concentrations of plasma cortisol, glucose, lactate, and ions for fish with combined landing and handling times of less than 2 min (rapid capture) and greater than 2 min (extended capture; adapted from Pankhurst and Dedual, 1994). Results on the initial physiological stress response exhibited by angled 
rainbow trout will be compared with results from previous investigations on the magnitude and duration of the stress response in rainbow trout.

\section{Materials and methods}

Adult rainbow trout were captured by hook-andline in July and August 2000, and June-August 2000 in the Alagnak River main stem and at Nonvianuk Lake outlet within Katmai National Park and Preserve (Fig. 1). Fish were captured at the outlets of Kukaklek and Nonvianuk lakes in June 2002. There were six methods of fishing used in this study: fly barbed circle hook, fly barbless circle hook, fly barbed J hook, fly barbless J hook, spin barbed J hook, and spin barbless J hook (Meka, 2004). Each angler was randomly assigned one of the six fishing methods twice daily. Sixand eight-weight fly rods and medium-action spinning rods were used with $8-10 \mathrm{lb}$ monofilament tippet or test line. The artificial lures and flies used were recommended by guides and anglers familiar with the Alagnak River rainbow trout fishery and were chosen by individual anglers each day per assigned fishing method. Fishing was conducted primarily from the shore on gravel bars; anglers generally cast upstream and drifted to a downstream direction. Anglers participating in this study included United States Geological Survey (USGS) biologists, Katmai National Park and Preserve biologists, Student Conservation Association volunteers, and volunteers from the general public and other government agencies. Angler experience was categorized as novice (fished $<10$ days over lifetime) or experienced (fished $>10$ days per year; Meka, 2004).

The times to land fish and remove hooks were recorded. Once a fish was hooked, other anglers stopped fishing and assisted with the sampling procedure, thus maintaining similar fishing effort. Handling time (hook removal) began when a fish was netted after landing until the angler removed the hook, and anglers were instructed to keep fish under water during the handling portion of capture to avoid any associated mortality due to air exposure (Bouck and Ball, 1966; Ferguson and Tufts, 1992). Anglers were instructed to land fish as they normally would while fishing recreationally, but not to play fish to exhaustion. However, in 2002 anglers were instructed to play some fish for more than 1 min while continuing to avoid exhausting fish, to obtain a broader range of sampling times.

Once the hooks were removed, fish were anesthetized in a rectangular container close to the area of capture with 251 of fresh river water and a concentration of $32 \mathrm{mg} / \mathrm{l}$ solution of clove oil (1:9 ratio clove oil mixed with ethanol; Anderson et al., 1997). Blood was withdrawn from the caudal vessels using heparinized syringes with 21 or 22 gauge needles. Plasma was separated immediately and stored in liquid nitrogen tanks in the field, and subsequently at $-80^{\circ} \mathrm{C}$ in the lab until further analysis. In addition to landing and hook removal times, the times to anesthetize fish, to withdraw

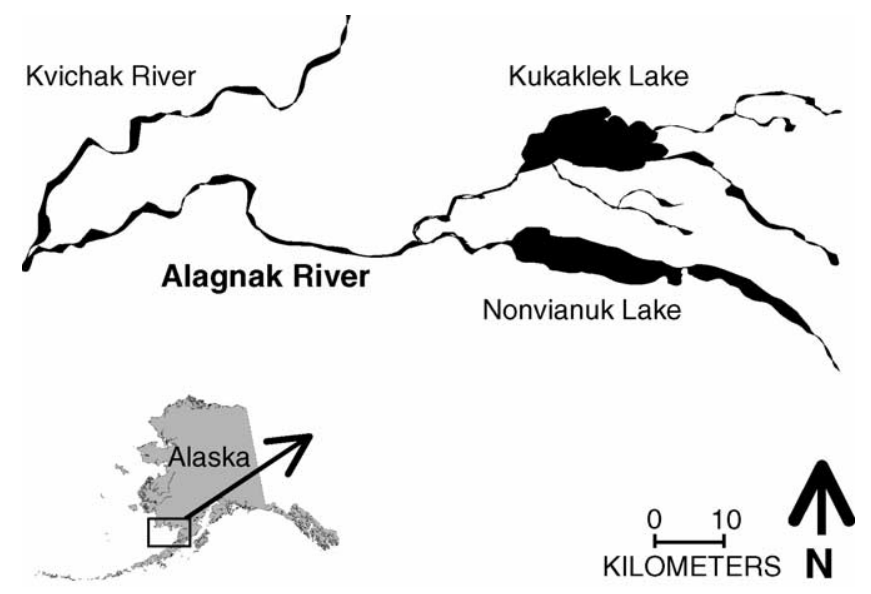

Fig. 1. Map of the Alagnak River watershed in southwest Alaska. Rainbow trout were captured by hook-and-line 2000-2002 on the Alagnak River main stem, and at the outlets of Kukaklek and Nonvianuk lakes. 
blood, and the total sampling time (from initial hooking until blood sampling was completed) were recorded. Fish were placed in another rectangular container with fresh river water to recover after blood was withdrawn. Fork length $(\mathrm{mm})$ and water temperature $\left({ }^{\circ} \mathrm{C}\right)$ near the area of capture were recorded. Fish were released near the area of capture following recovery. Blood sampling was always conducted by a biologist. Measurements were primarily taken by a biologist and occasionally volunteering anglers, under the supervision of a biologist.

The influences of landing time and of the time to remove hooks (i.e. angling duration) on physiological parameters were combined because both exhaustive exercise and handling stress have been shown to cause physiological changes in rainbow trout, and it was not feasible to separate their effects in this study (Pickering and Pottinger, 1989; Ferguson and Tufts, 1992). The amount of time fish were anesthetized in clove oil and sampled for blood under anesthesia was not included in analysis of the elevation of blood parameters because it was relatively short and similar for all fish (mean minutes:seconds \pm S.E., anesthesia 2:08 \pm 0:06, blood sampling 1:23 $\pm 0: 05)$. In addition, it has been demonstrated that the immediate physiological response by rainbow trout exposed to clove oil is minimal with short exposure times and most likely reflects stress prior to anesthesia (Wagner et al., 2002). Thus, landing time and the time required to remove hooks were considered to be the most influential to any physiological changes, due to the physically exhaustive nature of both stressors (Ferguson and Tufts, 1992; Booth et al., 1995). Fish were separated into rapid and extended capture groups because it has been demonstrated that physiological changes can occur within a few minutes after the onset of a stressor, therefore, the levels of blood parameters for rapid capture fish would potentially reflect the levels of free-swimming fish (Wydoski et al., 1976; Pankhurst and Dedual, 1994).

Plasma cortisol, glucose, ions (sodium, potassium, chloride; 2000 only), and lactate were analyzed at the USGS Conte Anadromous Fish Research Center (Turners Falls, MA, USA). Plasma cortisol was measured by a fully validated direct enzyme immunoassay (EIA) as outlined in Carey and McCormick (1998). Glucose was evaluated by the hexokinase and glucose6-phosphate dehydrogenase enzymatic method (Stein, 1963; McCormick and Bjornsson, 1994). Plasma lactate concentrations were determined by reduction of nicotinamide adenine dinucleotide with lactate dehydrogenase as described by Marbach and Weil (1967; see Carey and McCormick, 1998). Plasma cortisol, glucose, and lactate assays were run on a THERMOmax microplate reader using SOFTmax software (Molecular Devices, Menlo Park, CA, USA). Chloride, potassium, and sodium concentrations were determined by ion-selective electrodes (AVL Scientific Corp., model 9180, Roswell, GA, USA) using appropriate standards (McCormick and Bjornsson, 1994).

Multiple regressions with forward stepwise selection were conducted to determine the effects of combined landing and handling times, fish length, body condition, water temperature, and sampling year on concentrations of plasma cortisol, glucose, ions, and lactate. Body condition for captured fish was estimated by the residuals from a linear regression of weight on fork length, which has been demonstrated to remove the effects of size variation and is considered an appropriate condition index for the weight-length relationship in fish (Reist, 1985; Cone, 1989; Sutton et al., 2000). If significance was observed in relation to angling duration, one-way analysis of variance (ANOVA) was used to determine whether there were significant changes over time (by minute of angling duration) in extended capture fish. If significant differences were detected by ANOVA, data were analyzed by a Tukey-Kramer multiple comparisons test to compare mean plasma concentrations between extended capture and rapid capture groups, and to compare plasma concentrations per minute of angling duration in extended capture fish to the concentrations in rapid capture fish. Any influence of fish size on angling duration was evaluated by simple linear regression, and differences in fish length between rapid and extended capture groups were compared by a Tukey-Kramer multiple comparisons test. ANOVA was used to detect differences among years in water temperature, fish length, and angling duration. When necessary, landing and hook removal times and fish length and weight were log transformed to correct for non-normality of the data. In a concurrent study examining hooking injuries of Alagnak River rainbow trout from catch-and-release angling, the influence of fishing method, hook type, fish size and angler experience on angling duration were evaluated (Meka, 2004). These variables were not factored into the physiological data analysis, but provide insight into the fac- 
tors influencing angling duration (see Section 4). All statistical tests were conducted using SAS software (SAS Institute, Version 8) at the $\alpha<0.05$ significance level.

\section{Results}

Four hundred and fifteen rainbow trout were sampled during 2000-2002, with sample sizes per physiological parameter varying among years depending on catch success (Table 1). Immediate mortal-

Table 1

Water temperature, fork length, combined landing and handling times, and plasma cortisol, glucose, and lactate levels for rainbow trout captured by catch-and-release angling on the Alagnak River in 2000-2002

\begin{tabular}{|c|c|c|c|}
\hline & 2000 & 2001 & 2002 \\
\hline \multicolumn{4}{|c|}{ Water temperature $\left({ }^{\circ} \mathrm{C}\right)$} \\
\hline Mean & $12.2 \mathrm{a}$ & $13.2 \mathrm{~b}$ & $9.8 \mathrm{c}$ \\
\hline S.E. & 0.3 & 0.4 & 0.4 \\
\hline$N$ & 58 & 230 & 101 \\
\hline \multicolumn{4}{|c|}{ Fork length (mm) } \\
\hline Mean & $372 a b$ & $358 \mathrm{a}$ & $395 \mathrm{~b}$ \\
\hline S.E. & 23 & 16 & 16 \\
\hline$N$ & 58 & 230 & 101 \\
\hline \multicolumn{4}{|c|}{ Landing + hook removal time (minutes:seconds) } \\
\hline Mean & $3: 13 \mathrm{ab}$ & $2: 50 \mathrm{a}$ & $3: 46 \mathrm{~b}$ \\
\hline S.E. & $0: 20$ & $0: 10$ & $0: 19$ \\
\hline$N$ & 58 & 230 & 101 \\
\hline \multicolumn{4}{|c|}{ Plasma cortisol (ng/ml) } \\
\hline Mean & $17.0 \mathrm{a}$ & $15.8 \mathrm{a}$ & $6.8 \mathrm{~b}$ \\
\hline S.E. & 3.6 & 1.2 & 1.1 \\
\hline$N$ & 58 & 243 & 89 \\
\hline \multicolumn{4}{|c|}{ Plasma glucose (ng/ml) } \\
\hline Mean & $4.0 \mathrm{a}$ & $4.5 \mathrm{~b}$ & $4.2 \mathrm{ab}$ \\
\hline S.E. & 0.6 & 0.1 & 0.1 \\
\hline$N$ & 60 & 243 & 89 \\
\hline \multicolumn{4}{|c|}{ Plasma lactate $(\mathrm{mmol} / \mathrm{l})$} \\
\hline Mean & $6.4 \mathrm{a}$ & $7.1 \mathrm{a}$ & $5.3 \mathrm{~b}$ \\
\hline S.E. & 0.6 & 0.3 & 0.3 \\
\hline$N$ & 58 & 230 & 101 \\
\hline
\end{tabular}

Data are means \pm S.E. Significant differences among years do not share common letters $(P<0.05)$. Sample sizes were not uniform for plasma cortisol, glucose, or lactate each year because of occasional calibration errors in the laboratory (see also Table 2). Data used for temperature, length, and angling duration in this table were taken from captured fish with lactate samples. Thus, the sample sizes for these measurements reflect lactate sample sizes. ity was observed in seven fish $(2 \%, n=7 / 415)$ that most likely died due to hooking injuries that produced significant bleeding. Levels of plasma sodium (mean, $151.8 \pm 2.5 \mathrm{mmol} / \mathrm{l}, n=55)$, potassium $(3.29 \pm$ $0.18 \mathrm{mmol} / \mathrm{l}, n=52)$ and chloride $(138.8 \pm 2.0 \mathrm{mmol} / \mathrm{l}$, $n=55)$ in 2000 did not vary significantly in relation to angling duration, water temperature, fish length, or body condition, thus ions were not analyzed during 2001 and 2002. There was a year-effect observed in plasma cortisol, glucose, and lactate, thus each year of data was analyzed separately (Table 1). Multiple regressions with stepwise selection revealed significant influences to cortisol, glucose, and lactate concentrations by landing and handling time (cortisol, lactate), water temperature (cortisol, glucose, lactate), fish length (cortisol, glucose, lactate), and body condition (glucose, lactate), varying by year $(P<0.05$, Table 2$)$. Increasing angling duration produced a significant increase in levels of plasma cortisol and lactate during each year of the study $(P<0.05$, Fig. 2$)$. The aver-

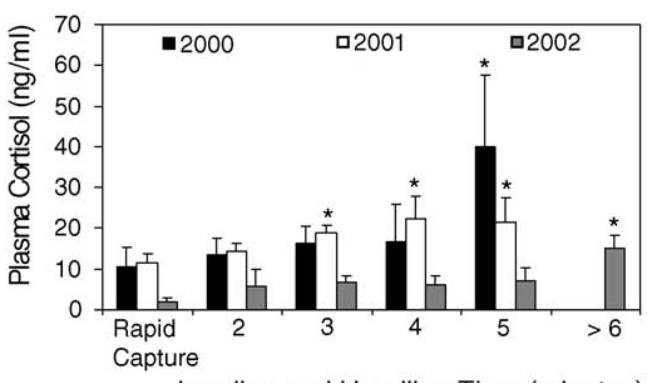

Landing and Handling Time (minutes)

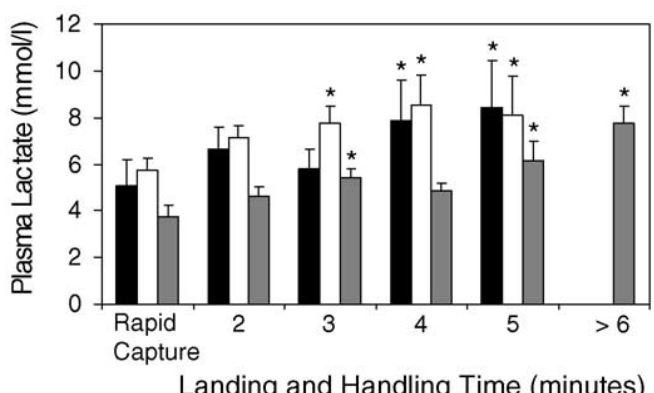

Fig. 2. Levels of plasma cortisol and lactate in Alagnak River rainbow trout angled and handled during the hook removal process from less than $2 \mathrm{~min}$ (rapid capture) to greater than $6 \mathrm{~min}$. Values are mean \pm S.E. Statistically significant elevations of cortisol and lactate above levels in rapid capture fish are indicated by asterisks $(P<0.05)$. Sample sizes by year are given in Table 2 . 
Table 2

Summary results of multiple regressions with stepwise selection to evaluate influences to changes in concentrations of plasma cortisol, glucose, and lactate in rainbow trout captured by angling (extended capture only)

\begin{tabular}{rrllll}
\hline Year & $N$ & Landing + hook removal time & Water temperature $\left({ }^{\circ} \mathrm{C}\right)$ & Fork length $(\mathrm{mm})$ & Body condition \\
\hline Cortisol & & & & & \\
2000 & 49 & $P=0.001 ; r^{2}=0.242$ & $P>0.111$ & $P>0.150$ & $P>0.150$ \\
2001 & 182 & $P=0.001 ; r^{2}=0.083$ & $P=0.001 ; r^{2}=0.146$ & $P>0.115$ & $P>0.150$ \\
2002 & 85 & $P=0.001 ; r^{2}=0.418$ & $P>0.150$ & $P=0.005 ; r^{2}=0.472$ & $P>0.150$ \\
Glucose & & & & \\
2000 & 49 & $P>0.150$ & $P>0.150$ & $P=0.001 ; r^{2}=0.261$ & $P>0.145$ \\
2001 & 178 & $P>0.150$ & $P=0.001 ; r^{2}=0.152$ & $P=0.026 ; r^{2}=0.176$ & $P=0.001 ; r^{2}=0.1 .00$ \\
2002 & 89 & $P>0.150$ & $P>0.150$ & $P>0.114$ & $P>0.150$ \\
Lactate & & & & \\
2000 & 47 & $P=0.05 ; r^{2}=0.270$ & $P=0.030 ; r^{2}=0.202$ & $P>0.150$ & $P>0.150$ \\
2001 & 171 & $P=0.009 ; r^{2}=0.179$ & $P=0.001 ; r^{2}=0.144$ & $P=0.009 ; r^{2}=0.449$ & $P>0.080$ \\
2002 & 91 & $P=0.001 ; r^{2}=0.339$ & $P=0.003 ; r^{2}=0.404$ & $P=0.022 ; r^{2}=0.112$ \\
\hline
\end{tabular}

The main-effects parameters included in the model were: combined landing and handling times (log-transformed), water temperature, fish length (fork length, log-transformed), and residual scores from the regression of log weight on log length (body condition). The sample sizes, significance level, and $r$-statistic are given for each regression.

age levels of cortisol and lactate for rapid capture fish were significantly lower than levels in extended capture fish $(P<0.009$, Fig. 2). Angling duration varied significantly by year, with the average landing and handling time for fish captured in 2000 and 2001 (mean minutes:seconds \pm S.E., 2:58 \pm 0:09) less than in 2002 (4:10 $\pm 0: 27)$ because anglers were instructed to play fish for longer amounts of time without exhausting fish $(P<0.006$; Table 1).

Fish length was positively related to glucose levels in 2000 and 2001 and cortisol and lactate levels in $2002(P<0.026$; Table 2$)$. Fish length was significantly related to angling duration during all years of the study $(P<0.001)$, and the average fork length $(\mathrm{mm})$ of rapid capture fish $(317 \mathrm{~mm} \pm 13)$ was significantly smaller than the average length of extended capture fish (383 $\mathrm{mm} \pm 10 ; P<0.051)$, i.e., larger fish took longer to land and handle than smaller fish. Fish size also varied significantly by year $(P<0.006)$, with larger fish captured in 2002 than in other years in addition to longer angling times (Table 1). These factors likely contributed to the significance of both fish size and angling duration for cortisol and lactate in the full models for 2002. The amount of time to anesthetize fish in clove oil did not vary significantly between rapid capture (mean \pm S.E., 2:13 $\pm 0: 11$ ) and extended capture (2:07 $\pm 0: 08)$ groups of fish $(P=0.510)$, indicating that fish size did not significantly influence anesthetization times. Weight/length residuals (i.e., body condition) were significantly related to plasma glucose (2001) and lactate $(2000,2001 ; P<0.022$, Table 2). Plasma glucose and lactate were significantly higher in fish with positive residuals (i.e., fish with greater weight per unit length) than fish with negative residuals. There was no significant effect of body condition on the duration of angling $(P>0.362)$.

Water temperature varied significantly between years (Table 1), and increases in plasma cortisol (2001),

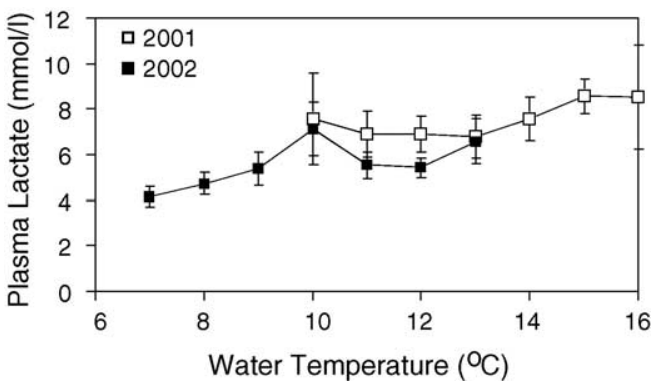

Fig. 3. Levels of plasma lactate in all Alagnak River rainbow trout captured by angling in $2001(n=173)$ and $2002(n=93)$ as a function of water temperature $\left({ }^{\circ} \mathrm{C}\right)$. Values are means \pm S.E. Changes in lactate concentrations were significantly related to temperature $(P<0.05$, ANOVA). Plasma lactate concentrations (two-sample $t$-test, $t=8.25$, d.f. $=261, P=0.001)$, and temperature $(t=14.70$, d.f. $=185, P=0.001)$ varied significantly by year. 

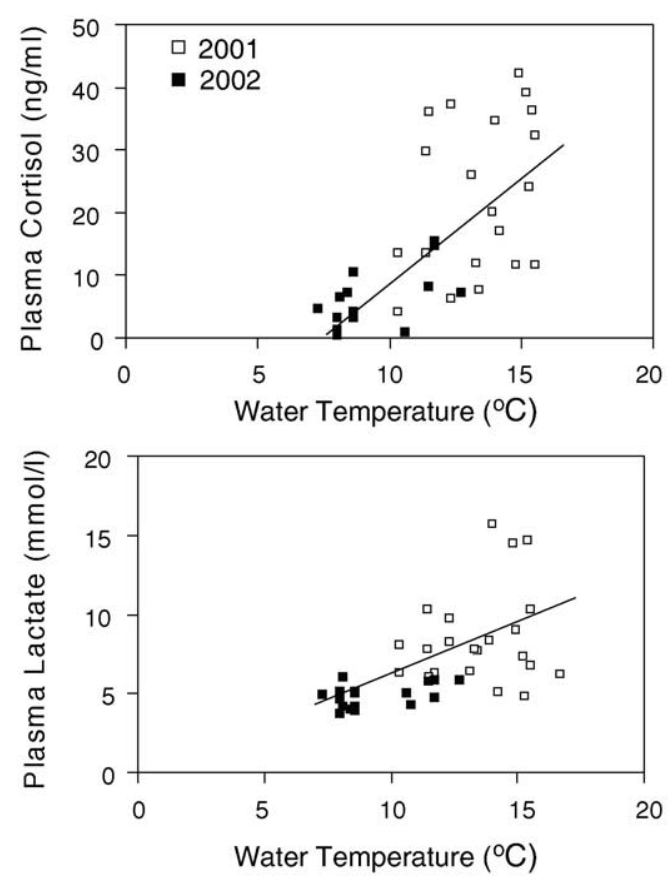

Fig. 4. Levels of plasma cortisol $(n=37)$ and lactate $(n=39)$ in Alagnak River rainbow trout captured during 2001 and 2002 with combined landing and handling times of $4 \mathrm{~min}$, as a function of water temperature $\left({ }^{\circ} \mathrm{C}\right)$. Changes in plasma cortisol and lactate concentrations were significantly related to temperature at $4 \mathrm{~min}$ capture time (cortisol $P=0.001, r^{2}=0.481$; lactate $P=0.001, r^{2}=0.331$; linear regression). Plasma cortisol and lactate concentrations (two-sample $t$-test; cortisol $t=5.13$, d.f. $=25, P=0.001$; lactate $t=5.53$, d.f. $=24$, $P=0.001)$ and temperature $(t=7.17$, d.f. $=35, P=0.001)$ varied significantly by year.

glucose (2001), and lactate (all years) levels were significantly related to increasing water temperature $(P<0.031$, Table 2). Temperatures in 2000 and 2001 were significantly higher than temperatures in 2002 , and levels of plasma cortisol and lactate in rapid and extended capture fish in 2000 and 2001 were significantly higher than corresponding levels in 2002 $(P<0.05$, Table 1, Fig. 3). This relationship was also apparent in fish with similar angling times $(P<0.001$, Fig. 4), indicating that plasma cortisol and lactate concentrations increased with the amount of time fish were angled regardless of the temperature range; however, the magnitude and range of the responses were higher in 2000-2001 when the temperatures were warmer.

\section{Discussion}

\subsection{Effects of angling duration}

Alagnak River rainbow trout exhibited increases in plasma cortisol and lactate with increases in the time fish were angled and handled during the hook removal process. Capture by angling is one of the most physically demanding forms of exercise stress in fish (Booth et al., 1995) and the subsequent physiological response has been demonstrated to increase with the amount of time fish are on the hook (Wydoski et al., 1976; Pankhurst and Dedual, 1994; Thorstad et al., 2003), sometimes resulting in high mortality rates (Bouck and Ball, 1966). Significant increases in plasma cortisol and lactate during this study were observed within 2-3 min of the initiation of angling and the highest levels were observed after 5-6 min of angling duration. Plasma cortisol levels in rapid capture fish were generally less than $11 \mathrm{ng} / \mathrm{ml}$ and reached over $39 \mathrm{ng} / \mathrm{ml}$ after 5-6 min of angling. Lactate levels in rapid capture fish were generally less than $5 \mathrm{mmol} / \mathrm{l}$ and reached over $8 \mathrm{mmol} / \mathrm{l}$ after 5-6 min of angling (Fig. 2). This time course was similar to other studies examining the response of both captive and wild populations of rainbow trout to acute stress. For example, captive rainbow trout subjected to $30 \mathrm{~s}$ of air exposure had a less severe cortisol response than fish handled and held in confinement for $1 \mathrm{~h}$ ( $<5$ to $40 \mathrm{ng} / \mathrm{ml}$ compared to $<5$ to $80 \mathrm{ng} / \mathrm{ml}$, respectively; Pickering and Pottinger, 1989). Pankhurst and Dedual (1994) observed wild rainbow trout captured by angling and played for less than $5 \mathrm{~min}$ to have less severe initial and peak levels of plasma cortisol $(<40 \mathrm{ng} / \mathrm{ml})$ and lactate $(<2 \mathrm{mmol} / \mathrm{l})$ than fish played for more than $15 \mathrm{~min}$ (cortisol, $>60 \mathrm{ng} / \mathrm{ml}$; lactate, $3.8 \mathrm{mmol} / \mathrm{l}$ ). Although the range of baseline and elevated levels vary by study from possible factors such as temperature and genetic differences, results from each study consistently demonstrated that the physiological disturbance increased with the duration of stress or exercise. Handling stress has also been demonstrated to cause significant physiological disruptions (Pickering and Pottinger, 1989; Ferguson and Tufts, 1992), and handling stress during the hook removal process is a concern among researchers examining the response of fish to angling (Cooke et al., 2001). We suggest that the initial slope of increase for levels of plasma cortisol and lactate in extended capture fish following landing 
and handling stress represents the early stages of a stress response that will continue to increase. Indeed, all of the physiological variables that we measured peaked some time after the stressor had been applied.

\subsection{Effects of size and body condition}

Larger fish had higher levels of plasma cortisol (2002), glucose $(2000,2001)$, and lactate (2002) levels. It has been demonstrated that large rainbow trout have greater levels of white muscle lactate and glucose than smaller fish, both during resting periods and after exhaustive exercise (Goolish, 1989; Kieffer, 1995). Because significantly greater levels of cortisol, glucose, and lactate in larger fish were not observed consistently throughout this study, it is difficult to interpret the significance of fish size. There was a strong correlation between landing time and fish size, and fish captured in 2002 were significantly larger and played for longer than in other years. It is possible that larger fish captured in 2002 and longer landing times produced a sizeeffect in cortisol and lactate, and it is also possible that larger fish exhibited a greater physiological response than smaller fish captured in similar conditions. Thus, fish size should be considered an important source of variability to the physiological disturbance of rainbow trout captured by angling.

Fish with positive weight/length regression residuals had higher levels of lactate $(2000,2001)$ and glucose (2001). The use of the weight/length residuals index is a measure similar to other measures of body condition or condition factor (e.g., Fulton's $K$, relative weight). In its simplest interpretation it is a measure of body shape, and while it has been used to estimate the energetic state of fish, this relationship may not always be accurate (Sutton et al., 2000). Few studies have examined the relationship between body condition and the physiological response to exhaustive exercise in fish. Brobbel et al. (1996) reported that condition factor was highest in bright Atlantic salmon (Salmo salar) angled to exhaustion compared to levels in kelts, and bright salmon took significantly longer to angle. The positive relationship between weight/length residuals and plasma lactate suggests that more 'robust' fish (higher weight/length ratio) experienced more anaerobic exercise during angling than less robust fish. Similarly, the positive relationship with plasma glucose suggests that fish with higher weight/length ratio had a larger secondary stress response. Whether these relationships had more to do with the shape of the animals, their energetic state or some other factor related to the weight/length ratio will require further investigation.

\subsection{Effects of temperature}

The average water temperature in this study, as well as levels of plasma cortisol and lactate in rapid and extended capture fish, was higher in 2001 than in 2002. The pattern of increase in the physiological response was likely due to the amount of time fish were angled, yet the magnitude of the response was also a reflection of the range of water temperatures each year. What is apparent from Figs. 3 and 4 is that the temperature can affect the magnitude of the response, but does not necessarily induce a greater response. In other words, rainbow trout captured at warmer temperatures can exhibit greater increases in plasma cortisol and lactate, but there are many fish that did not show substantial increases in these parameters at higher temperatures. In addition to indicating an important role for temperature, this result indicates that there must be other, unmeasured factors that determine the magnitude of the response to angling. Differences in the exercise intensity and the individual responses of fish to exercise intensity may be among these unmeasured factors.

Fish acclimated to seasonally fluctuating water temperatures may experience equivocal patterns of physiological response to similar types of stress, yet there may be differences in basal and elevated levels depending on the range of temperatures (Barton and Schreck, 1987; Barrett and McKeown, 1989; Kieffer et al., 1994). For example, exhaustively exercised rainbow trout captured at $18{ }^{\circ} \mathrm{C}$ had significantly greater plasma lactate concentrations than fish captured at $5{ }^{\circ} \mathrm{C}$, yet resting levels of lactate were similar (Kieffer et al., 1994). Largemouth bass (Micropterus salmoides) captured by hook-and-line during March, May, and July, when seasonal temperatures increased over time, had levels of blood lactate that reflected the range of water temperatures (Gustaveson et al., 1991). Groups of largemouth bass captured within the three temperature ranges all experienced increases in blood lactate as the duration of hooking time increased, yet fish captured at the warmest temperatures had higher basal and elevated (from angling) lactate levels than fish captured at the cooler temperatures. Water temperature likely 
influenced the range of cortisol and lactate levels in this study, and landing and hook removal times and other, unmeasured factors influenced the magnitude and rate of elevation of cortisol and lactate for individual fish.

\subsection{Effects of anesthesia}

In previous studies where the relationship between capture by angling and the subsequent physiological response was examined, fish were typically anesthetized in a tricaine methanesulfonate (MS-222) solution before blood sampling, and the times in anesthesia and for blood withdrawal were generally not factored into the analysis (Wydoski et al., 1976; Booth et al., 1995; Brobbel et al., 1996). The physiological stress response of fish anesthetized in MS-222 or clove oil solution has ranged from minimal to significant, largely depending on the duration of time fish are in the anesthetic, the specific anesthetic and dose, when the dose was delivered, and the species of study (Barton and Peter, 1982; Tort et al., 2002; Wagner et al., 2002). It should be recognized that some of the variation observed in physiological parameters measured when fish are under anesthesia following a stress event may be partially due to differences in anesthetization times, which can contribute to variation in sampling times and ultimately physiological changes. It has been demonstrated in adult rainbow trout that exposure to clove oil similar to the dose and induction time used in this study (2-3 min per individual fish) resulted in a minimal increase in plasma cortisol and the stress response was likely caused by initial crowding during transport to anesthesia baths (Wagner et al., 2002). A recent study found that rainbow trout handled and subsequently anesthetized with MS-222 or clove oil experienced a lower lactate response and suppressed cortisol response compared with fish handled without anesthesia (Wagner et al., 2003). Because we observed levels of plasma cortisol and lactate to increase with the duration of angling, we likely measured the continuing response to the duration of landing and hook removal times due to the exhaustive nature involved in landing and handling fish. It should be noted that the use of clove oil in this study might have slightly reduced the observed plasma cortisol and lactate levels that might have been observed had anesthesia not been used.

\subsection{Baseline levels of physiological parameters}

Levels of plasma cortisol for rapid capture fish identified in this study were within the range of resting or baseline levels previously reported for rainbow trout (Woodward and Strange, 1987; Pankhurst and Dedual, 1994). However, levels of plasma lactate for rapid capture fish were higher than resting levels previously reported for wild (Pankhurst and Dedual, 1994) and hatchery (Milligan and Girard, 1993) rainbow trout. One of the greatest challenges to effectively monitor the physiological response of wild fish to capture stress is the ability to establish baseline values of blood chemistry (Wydoski et al., 1976). Because the lowest lactate levels observed in this study were higher than the reported resting levels observed by Pankhurst and Dedual (1994), it seems likely there is either a basic difference in the physiological state of rainbow trout between studies or true baseline values were not observed because levels increased immediately after hooking.

Minimal significant changes in plasma glucose and no significant changes in ions were observed in this study, and the levels of glucose and ions were within baseline ranges previously reported (Wedemeyer et al., 1990). Typically, a net loss of sodium and chloride ions is observed following exhaustive exercise or stress in salmonids in freshwater, but usually takes hours to manifest (Brobbel et al., 1996; Carey and McCormick, 1998). Plasma glucose has been observed to increase significantly $5 \mathrm{~min}$ after the onset of hooking stress in rainbow trout, particularly for fish acclimated to higher temperatures (12 and $20^{\circ} \mathrm{C}$; Wydoski et al., 1976). However, in numerous controlled studies on the effect of stressors, it has been observed to take up to an hour to see significant increases in plasma glucose (Ristori and Laurent, 1985; Carey and McCormick, 1998). Although we found a significant relationship between glucose and length in 2000 and 2001, and glucose, temperature, and body condition in 2001, it is difficult to interpret the significance of the results because the levels of glucose were typical of resting levels previously recorded for rainbow trout. The small changes in glucose likely resulted in response to variations in fish size, condition, and water temperature, yet the absence of significant increases in plasma ions and glucose (beyond those reported) is likely due to the relatively short time frame within which samples were taken. 


\subsection{Recovery and mortality}

In general, the amount of time required for plasma cortisol to recover to resting levels following an acute stress event is within 24 h (Barton et al., 1986; Pickering and Pottinger, 1989; Pankhurst and Dedual, 1994). The magnitude of a stress response and recovery time can vary depending on the severity and duration of stress, fish size, temperature, recovery conditions, developmental state, and origin of fish (e.g., stock or hatchery versus wild; Wydoski et al., 1976; Mazeaud et al., 1977; Woodward and Strange, 1987; Pickering and Pottinger, 1989; Pankhurst and Dedual, 1994; Carey and McCormick, 1998). Alagnak River rainbow trout with greater landing and handling times presumably experienced a greater peak plasma cortisol and lactate response and longer recovery period than fish captured more quickly. Studies have found mortality from exhaustive exercise to manifest in hours to several days after the exercise event (Black, 1958; Dotson, 1982; Brobbel et al., 1996; Wilkie et al., 1996). Although minimal immediate mortality was observed in this study, it is difficult to predict the recovery times or delayed mortality rates of captured fish because they were not held after capture for observation or repeat sampling.

While the precise cause of mortality from exhaustive exercise is unknown, it has been postulated to result from an intracellular acid-base disturbance produced in part by the generation of lactic acid in the muscle (Wood et al., 1983). Plasma lactate is an indirect outcome of this generation of muscle lactic acid, and several studies have found elevated lactate associated with delayed mortality following exercise or hypoxia (Wood et al., 1983; Ferguson and Tufts, 1992; van Raaij et al., 1996). However, this relationship is not found in all species (see Davis et al., 2001), nor do we have enough information to establish a threshold for plasma lactate (or other parameters) that would allow for a predictive index of determining when mortality would occur. Although fish in this study were not played to exhaustion and most fish experienced short landing and hook removal times, many fish experienced plasma lactate levels that were three times higher than levels for rapid capture fish, sufficiently high to suggest the possibility of delayed mortality. In the future it would be worthwhile to hold angled fish for an extended period under controlled conditions or release fish with telemetry transmitters or some other long-term individual marker (e.g., PIT tags, external tags for angler recaptures) to determine if delayed mortality in fact may be occurring.

\subsection{Potential sublethal impacts}

The observed increases in plasma cortisol and lactate in this study may be indicative of exercise and stress responses that could have produced sublethal disturbances in individual rainbow trout. For example, the cessation of feeding after exposure to acute stress events has been demonstrated in salmonids, sometimes resulting in a reduction of growth (Pickering et al., 1982; McCormick et al., 1998), presumably through the effect of cortisol (Gregory and Wood, 1999). It has been demonstrated that multiple acute stress events caused a cumulative physiological response in fish (Barton et al., 1986), yet the impact on feeding behavior and growth in wild trout subjected to an angling stress event or multiple captures over a period of a few months has not been investigated to our knowledge. Meka (2004) demonstrated that the use of barbed J hooks took significantly longer to remove than barbless hooks in Alagnak River rainbow trout, and experienced anglers took longer to land fish than novice anglers because they captured larger fish. These results apply directly to the Alagnak River rainbow trout fishery, but should be considered representative of other popular catch-and-release rainbow trout fisheries in Alaska and elsewhere. It is imperative to educate anglers on the significance of using terminal tackle to reduce handling time after capture, and to realize that the physiological response of larger fish may be greater because they take longer to land. This may be of great importance in sport fisheries where trophy-sized trout are sought after and gear choices are suited to capture larger fish. Minimizing the amount of time fish are landed and handled during the angling process will likely reduce the peak physiological response and duration of recovery of angled fish, particularly at warmer water temperatures. Managers will need to carefully consider whether these physiological changes are sufficient to have long-term impacts on individual trout, and to specifically evaluate the impacts of multiple recaptures on individual rainbow trout, and trout populations. These recommendations emphasize the necessity of making the results from catch-and-release research available to the angling public, researchers, and fisheries managers, and for future research and management decisions to fo- 
cus on reducing sublethal disturbances in addition to mortality.

\section{Acknowledgements}

The authors thank the many individuals who participated in the field aspect of this study, especially: R. Beatty, R. D’Ambruoso, B. Frampton, R. Gray, D. Parker, D. Oswald, P. Richards, D. Wilson, and C. Wall. We thank J. Nielsen and T. Hamon for creating the original study proposal and thorough reviews of this manuscript. We thank J. Margraf and N. Hughes for their guidance and critical reviews of this manuscript. Thank you to A. Moeckel, D. Lerner, and M. Monette for their assistance in the lab analysis and interpretation, and helpful comments on the manuscript.

\section{References}

Anderson, W.G., McKinley, R.S., Colavecchia, M., 1997. The use of clove oil as an anesthetic for rainbow trout and its effects on swimming performance. N. Am. J. Fish. Manage. 17, 301-307.

Barrett, B.A., McKeown, B.A., 1989. Plasma growth hormone levels in Salmo gairdneri: studies on temperature and exercise intensity/duration relationships. Comp. Biochem. Physiol. 94, 791-794.

Barton, B.A., Peter, R.E., 1982. Plasma cortisol stress response in fingerling rainbow trout, Salmo gairdneri Richardson, to various transport conditions, anesthesia, and cold shock. J. Fish Biol. 20, 39-51.

Barton, B.A., Schreck, C.B., 1987. Influences of acclimation temperature on interregnal and carbohydrate stress responses in juvenile chinook salmon (Oncorhynchus tshawytscha). Aquaculture 62, 299-310.

Barton, B.A., Schreck, C.B., Sigismondi, L.A., 1986. Multiple acute disturbances evoke cumulative physiological stress responses in juvenile salmon. Trans. Am. Fish. Soc. 115, 245-251.

Black, E.C., 1958. Hyperactivity as a lethal factor in fish. J. Fish. Res. Bd. Canada 15, 573-586.

Booth, R.K., Kieffer, J.D., Davidson, K., Bielak, A.T., Tufts, B.L., 1995. Effects of late-season catch and release angling on anaerobic metabolism, acid-base status, survival, and gamete viability in wild Atlantic salmon (Salmo salar). Can. J. Fish. Aquat. Sci. 52, 283-290.

Bouck, G.R., Ball, R.C., 1966. Influence of capture methods on blood characteristics and mortality in the rainbow trout (Salmo gairdneri). Trans. Am. Fish. Soc. 95, 170-176.

Brobbel, M.A., Wilkie, M.P., Davidson, K., Kieffer, J.D., Bielak, A.T., Tufts, B.L., 1996. Physiological effects of catch and release angling in Atlantic salmon (Salmo salar) at different stages of freshwater migration. Can. J. Fish. Aquat. Sci. 53, 2036-2043.
Campbell, P.M., Pottinger, T.G., Sumpter, J.P., 1992. Stress reduces the quality of gametes produced by rainbow trout. Biol. Reprod. 47, 1140-1150.

Carey, J.B., McCormick, S.D., 1998. Atlantic salmon smolts are more responsive to an acute handling and confinement stress than parr. Aquaculture 168, 237-253.

Cone, R.S., 1989. The need to reconsider the use of condition indices in fishery science. Trans. Am. Fish. Soc. 118, 510-514.

Cooke, S.J., Hogle, W.J., 2000. Effects of retention gear on the injury and short-term mortality of adult smallmouth bass. N. Am. J. Fish. Manage. 20, 1033-1039.

Cooke, S.J., Philipp, D.P., 2004. Behavior and mortality of caughtand-released bonefish (Albula spp.) in Bahamian waters with implications for a sustainable recreational fishery. Biol. Conserv. 118, 599-607.

Cooke, S.J., Barthel, B.L., Suski, C.D., 2003. Effects of hook type on injury and capture efficiency of rock bass, Ambloplites rupestris, angled in south-eastern Ontario. Fish. Manage. Ecol. 10, 269-271.

Cooke, S.J., Philipp, D.P., Dunmall, K.M., Schreer, J.F., 2001. The influence of terminal tackle on injury, handling time, and cardiac disturbance of rock bass. N. Am. J. Fish. Manage. 21, 333342.

Cooke, S.J., Philipp, D.P., Schreer, J.F., McKinley, R.S., 2000. Locomotory impairment of nesting male largemouth bass following catch-and-release angling. N. Am. J. Fish. Manage. 20, 68977.

Cooke, S.J., Schreer, J.F., Dunmall, K.M., Philipp, D.P., 2002. Strategies for quantifying sublethal effects of marine catch-and-release angling: insights from novel freshwater applications. Am. Fish. Soc. Symp. 30, 121-134.

Davis, M.W., Olla, B.L., Schreck, C.B., 2001. Stress induced by hooking, net towing, elevated sea temperature and air in sablefish: lack of concordance between mortality and physiological measures of stress. J. Fish Biol. 58, 1-15.

Dotson, T., 1982. Mortalities in trout caused by gear type and anglerinduced stress. N. Am. J. Fish. Manage. 2, 60-65.

Ferguson, R.A., Tufts, B.L., 1992. Physiological effects of brief air exposure in exhaustively exercised rainbow trout (Oncorhynchus mykiss): implications for "catch and release" fisheries. Can. J. Fish. Aquat. Sci. 49, 1157-1162.

Goolish, E.M., 1989. The scaling of aerobic and anaerobic muscle power in rainbow trout (Salmo gairdneri). J. Exp. Biol. 147, 493-505.

Gregory, T.R., Wood, C.M., 1999. The effects of chronic plasma cortisol elevation on the feeding behaviour, growth, competitive ability, and swimming performance of juvenile rainbow trout. Physiol. Biochem. Zool. 72, 286-295.

Gustaveson, A.W., Wydoski, R.S., Wedemeyer, G.A., 1991. Physiological response of largemouth bass to angling stress. Trans. Am. Fish. Soc. 120, 629-636.

Kieffer, J.D., 1995. The role of body size and temperature in the physiological response to exercise in fish. PhD Dissertation. Queen's University at Kingston, Kingston, Ont., Canada.

Kieffer, J.D., Currie, S., Tufts, B.L., 1994. Effects of environmental temperature on the metabolic and acid-base responses of rainbow trout to exhaustive exercise. J. Exp. Biol. 194, 299-317. 
Kieffer, J.D., Kubacki, M.R., Phelan, F.J.S., Philipp, D.P., Tufts, B.L., 1995. Effects of catch-and-release angling on nesting male smallmouth bass. Trans. Am. Fish. Soc. 124, 70-76.

Lewynsky, V.A., Bjornn, T.J., 1987. Response of cutthroat and rainbow trout to experimental catch-and-release fishing. Am. Fish. Soc. Symp. 30, 16-32.

McCormick, S.D., Bjornsson, B.T., 1994. Physiological and hormonal differences among Atlantic salmon parr and smolts reared in the wild, and hatchery smolts. Aquaculture 121, 235-244.

McCormick, S.D., Shrimpton, J.M., Carey, J.B., O’Dea, M.F., Sloan, K.E., Moriyama, S., Bjornsson, B.T., 1998. Repeated acute stress reduces growth rate of Atlantic salmon parr and alters plasma levels of growth hormone, insulin-like growth factor I and cortisol. Aquaculture 168, 221-235.

McLaughlin, S.A., Grizzle, J.M., Whiteley, H.E., 1997. Ocular lesions in largemouth bass, Micropterus salmoides, subjected to the stresses of handling and containment. Vet. Comp. Ophthalmol. 7, 5-9.

Mäkinen, T.S., Niemeliä, E., Moen, K., Lindström, R., 2000. Behavior of gill-net and rod-captured Atlantic salmon (Salmo salar L.) during upstream migration and following radio tagging. Fish. Res. 45, 117-127.

Marbach, E.P., Weil, M.H., 1967. Rapid enzymatic measurement of blood lactate and pyruvate. Clin. Chem. 13, 314.

Mazeaud, M.M., Mazeaud, F., Donaldson, E.M., 1977. Primary and secondary effects of stress in fish: some new data with a general review. Trans. Am. Fish. Soc. 106, 201-212.

Meka, J.M., 2004. The influence of hook type, angler experience, and fish size on injury rates and the duration of capture in an Alaskan catch-and-release rainbow trout fishery. N. Am. J. Fish. Manage. 24, 1299-1311.

Meka, J.M., Knudsen, E.E., Douglas, D.C., Benter, R.B., 2003. Variable migratory patterns of different rainbow trout life history types in a southwest Alaska watershed. Trans. Am. Fish. Soc. $132,717-732$

Milligan, C.L., Girard, S.S., 1993. Lactate metabolism in rainbow trout. J. Exp. Biol. 180, 175-193.

Muoneke, M.I., Childress, W.M., 1994. Hooking mortality: a review for recreational fisheries. Rev. Fish. Sci. 2, 123-126.

Pankhurst, N.W., Dedual, M., 1994. Effects of capture and recovery on plasma levels of cortisol, lactate and gonadal steroids in a natural population of rainbow trout. J. Fish Biol. 45, 1013-1025.

Pickering, A.D., Pottinger, T.G., 1989. Stress responses and disease resistance in salmonid fish: effects of chronic elevation of cortisol. Fish Physiol. Biochem. 7, 253-258.

Pickering, A.D., Pottinger, T.G., Christie, P., 1982. Recovery of brown trout, Salmo trutta L., from acute handling stress: a timecourse study. J. Fish Biol. 20, 229-244.

Reist, J.D., 1985. An empirical evaluation of several univariate methods that adjust for size variation in morphometric data. Can. J. Zool. 63, 1429-1439.

Ristori, M.T., Laurent, P., 1985. Plasma catecholamines and glucose during moderate exercise in the trout: comparison with bursts of violent activity. Exp. Biol. 44, 247-253.
Stein, M.W., 1963. D-Glucose, determination with hexokinase and glucose-6-phosphate dehydrogenase. In: Bergmeyer, H.U. (Ed.), Methods in Enzymatic Analysis. Academic Press, New York, pp. 117-122.

Sutton, S.G., Bult, T.P., Haedrich, R.L., 2000. Relationships among fat weight, body weight, water weight, and condition factors in wild Atlantic salmon parr. Trans. Am. Fish. Soc. 129, 527538.

Thorstad, E.B., Næsje, T.F., Fiske, P., Finstad, B., 2003. Effects of hook and release on Atlantic salmon in River Alta, northern Norway. Fish. Res. 60, 293-307.

Titus, R.G., Vanicek, C.D., 1988. Comparative hooking mortality of lure-caught Lahontan cutthroat trout at Heenan Lake, California. Calif. Fish Game 74, 218-225.

Tort, L., Puigcerver, M., Crespo, S., Padrós, F., 2002. Cortisol and haematological response in sea bream and trout subjected to the anaesthetics clove oil and 2-phenoxyethanol. Aquacult. Res. 33, 907-910.

Tufts, B.L., Tang, Y., Tufts, K., Boutilier, R.G., 1991. Exhaustive exercise in "wild" Atlantic salmon (Salmo salar): acid-base regulation and blood gas transport. Can. J. Fish. Aquat. Sci. 48, 868-874.

van Raaij, M.T.M., Pit, D.S.S., Balm, P.H.M., Steffens, A.B., Vandenthillart, G.E.E.J.M., 1996. Behavioral strategy and the physiological stress response in rainbow trout exposed to severe hypoxia. Hormones Behav. 30, 85-92.

Wagner, E., Arndt, R., Hilton, B., 2002. Physiological stress responses, egg survival and sperm motility for rainbow trout broodstock anesthetized with clove oil, tricaine methanesulfonate or carbon dioxide. Aquaculture 211, 353-366.

Wagner, G.N., Singer, T.D., McKinley, R.S., 2003. The ability of clove oil and MS-222 to minimize handling stress in rainbow trout (Oncorhynchus mykiss Walbaum). Aquacult. Res. 34, 1139-1146.

Wedemeyer, G.A., Barton, B.A., McLeay, D.J., 1990. Stress and acclimation. In: Schreck, C.B., Moyle, P.B. (Eds.), Methods for Fish Biology. American Fisheries Society, Bethesda, MD, pp. 451-489.

Wilkie, M.P., Davidson, K., Brobbel, M.A., Kieffer, J.D., Booth, R.K., Bielak, A.T., Tufts, B.L., 1996. Physiology and survival of wild Atlantic salmon following angling in warm summer waters. Trans. Am. Fish. Soc. 125, 572-580.

Wood, C.M., Turner, J.D., Graham, M.S., 1983. Why do fish die after severe exercise? J. Fish Biol. 22, 189-201.

Woodward, C.C., Strange, R.J., 1987. Physiological stress responses in wild and hatchery-reared rainbow trout. Trans. Am. Fish. Soc. 116, 574-579.

Wright, S., 1972. A review of the subject of hooking mortalities in Pacific Salmon (Oncorhynchus). Pac. Mar. Fish. Comm. Annu. Rep. 23, 47-65.

Wydoski, R.S., Wedemeyer, G.A., Nelson, N.C., 1976. Physiological response to hooking stress in hatchery and wild rainbow trout (Salmo gairdneri). Trans. Am. Fish. Soc. 105, 601606. 